\title{
Design and characterisation of colloidal nanocarriers for enhanced skin delivery of etodolac
}

\author{
Güler SARIBEY 1 (D), Emine KAHRAMAN 1 (D), Meryem Sedef ERDAL 1 (D), Sevgi GÜNGÖR 1 * (D) \\ 1 Department of Pharmaceutical Technology, Faculty of Pharmacy, İstanbul University, Beyazit 34116 İstanbul, \\ Turkey. \\ * Corresponding Author. E-mail: sgungor@istanbul.edu.tr (S.G.); Tel. +90-212-440 00 00-13493.
}

Received: 15 October 2020 / Revised: 05 December 2020/ Accepted: 08 December 2020

\begin{abstract}
The aim of this work was to develop colloidal nanocarriers for skin delivery of etodolac (ETD), which is a non-steroidal anti-inflammatory drug orally used for the management of acute pain and inflammation, but leads to unfavourable effects on the stomach. The oleic acid and blend of Labrasol/Trancutol $\mathrm{P}$ were used as oil phase and surfactant/co-surfactant mixture in the microemulsion formulations, respectively. ETD loaded microemulsions selecting the microemulsion region of pseudo-ternary phase diagrams were prepared, and then the microemulsions were characterised to confirm formation of oil in water microemulsions via optical isotropy, refractive index, droplet size, electrical conductivity, rheological behaviour and morphological analysis. In vitro permeation of ETD through porcine skin was evaluated using Franz diffusion cells for stable ETD loaded microemulsions. ATR-FTIR spectroscopy analysis was performed to elucidate interaction between the microemulsion components and stratum corneum structure on the molecular level. Confocal laser scanning microscopy analysis was further carried out to visualize skin penetration enhancement effect of the microemulsion formulation consisting of a model lipophilic fluorescent marker, Nile Red. The results indicated that the developed microemulsion formulation consisting of oleic acid, Labrasol, Transcutol $\mathrm{P}$ and water offer a potential approach to enhance skin delivery of ETD for topical treatment of inflammatory diseases.
\end{abstract}

KEYWORDS: Microemulsions; colloidal nanocarriers; non-steroidal anti-inflammatory drugs; etodolac; skin delivery; topical treatment.

\section{INTRODUCTION}

Non-steroidal anti-inflammatory drugs (NSAIDs) are extensively prescribed analgesics for the management of acute pain and inflammation leaded by chronic musculo-skeletal diseases such as rheumatoid arthritis, osteoarthritis, tendinitis, bursitis [1,2]. However, orally administration of these drugs triggers to unfavourable effects specifically on the stomach as the results of inhibition of prostaglandins protecting gastric mucosa and acidic characters of the drugs [2]. In addition, most of NSAIDs have cardiovascular side effects and renal toxicity [3]. To overcome these drawbacks, some NSAIDs are administered percutaneously and topically to achieve local effect because inflammation commonly affects local part of the body [4].

In dermal administration, drug molecules should be small molecular weight $(<500 \mathrm{Da}$ of molecular weight) and moderately lipophilic (log P 1-3), to reach deeper layers of the skin and/or to enter systemic circulation passing the stratum corneum layer, which is an efficient barrier for skin delivery $[5,6]$. Etodolac (ETD) is a feasible candidate with 2.8 of Log P value and $287.35 \mathrm{Da}$ of molecular weight for topical administration [7], which is an orally administered selective cyclooxygenase-2 (COX-2) inhibitor in relieving inflammation and associated pain. Its oral administration can lead to gastrointestinal and cardiac side effects [3]. Taking into account its promising physicochemical properties for skin delivery, and disadvantageous of systemic ETD use, additionally to deliver pharmacologically efficient amounts of ETD to target area of the disease, topical application of ETD would offer a convenient solution overcoming the limitations of its oral administration. However, there is still a need to enhance topical delivery of ETD due to the poor solubility of ETD, restricting its dosing options [7].

Microemulsion formulations are one of the most promising delivery system for topical administration NSAIDs [8]. They are thermodynamically stable colloidal nanocarriers formulated using isotropic mixture of

How to cite this article: Sarıbey G, Kahraman E, Erdal MS, Güngör S. Design and characterisation of colloidal nanocarriers for enhanced skin delivery of etodolac. J ResPharm. 2021; 25(1): 22-33. 
oil, surfactant, co-surfactant and drug molecules [9-11]. Considering of their composition, it is suggested that the microemulsions have relatively high drug solubility capacity resulted in increased thermodynamic activity and then transdermal flux of the drug molecules [12-15]. Moreover, these systems lead to increased drug permeation through the skin because of microemulsion components acting as penetration enhancers $[10,16]$. Regarding in improvement of solubility and skin permeation of drug molecules, the microemulsions have superiorities over the other drug delivery systems.

Many surfactants and co-surfactants in the microemulsion formulation can form a stable interfacial film between oil and water. Moreover, the surfactant and co-surfactant contained in the microemulsion can act as penetration enhancers. Transcutol $\mathrm{P}$, the highly purified diethylene glycol monoethyl ether, is a wellknown penetration enhancer in skin delivery and by its amphiphilic nature it has been known to reduce the interfacial tension resulting in balanced microemulsions systems [17]. Transcutol $\mathrm{P}$ can diffuse into the stratum corneum and alter the solubility parameter of the intercellular lipid domain [18].

The choice of components of the oil phase in microemulsions may also influence drug release, drug solubilisation in the microemulsion, and drug skin permeability. Oleic acid is one of the most frequently selected oil in microemulsion systems and, it has been demonstrated that oleic acid containing microemulsions increased the penetration of lipophilic drugs through the skin. It has been reported that oleic acid might increase the epidermal permeability through a mechanism involving the perturbation of stratum corneum lipid bilayers $[19,20]$.

In the view of this information, aim of the present study was to formulate, characterise, and evaluate microemulsion-type nanocolloidal carrier formulations for effective skin delivery of ETD. Three microemulsion formulations consisting of oleic acid (oil phase), Labrasol (surfactant), Transcutol P (cosurfactant), and water were developed by constructing phase diagrams and characterized by isotropy, particle size and size distribution, $\mathrm{pH}$, conductivity, refractive index, and viscosity. The permeation of ETD through the skin was evaluated by means of Franz diffusion cells using excised porcine skin. Poorly soluble molecule's delivery efficiency from the microemulsions into the skin layers was visualized using a lipophilic fluorescent dye (Nile Red) as a lipophilic model fluorescent compound by confocal laser scanning microscopy (CLSM). Additionally, the interaction of microemulsion components with stratum corneum lipids on molecular levels was investigated by Attenuated Total Reflectance Fourier Transformed Infrared (ATRFTIR) spectroscopy.

\section{RESULTS AND DISCUSSION}

The most important parameter for microemulsion formation is solubility of poorly soluble drug substance in the microemulsion components [15]. Thus, solubility of ETD was determined in oleic acid, Transcutol $\mathrm{P}$ and Labrasol. Its solubility was found $12.63 \pm 1.07 \mathrm{mg} / \mathrm{mL}$ in oleic acid used as oil phase. Besides, it exhibited a high solubility in Transcutol $\mathrm{P}$ and Labrasol $(34.50 \pm 2.72$ and $86.63 \pm 2.75 \mathrm{mg} / \mathrm{mL}$, respectively), supporting conformity for formation of ETD loaded microemulsions. Following solubility studies, pseudo-ternary phase diagrams were constructed to determine appropriate concentration ranges of components (aqueous phase, oil phase, surfactant and co-surfactant) in the regions of forming microemulsions. A representative pseudo-ternary phase diagram of microemulsions composed of oleic acid, Labrasol and Transcutol P with Km 1:1 is shown in Figure 1. The transparent microemulsion region is shaded in the phase diagram. The rest of region on the phase diagram represents turbid and conventional emulsions based on visual observation. Also, no liquid crystalline structure was observed in cross polarized light microscopy images.

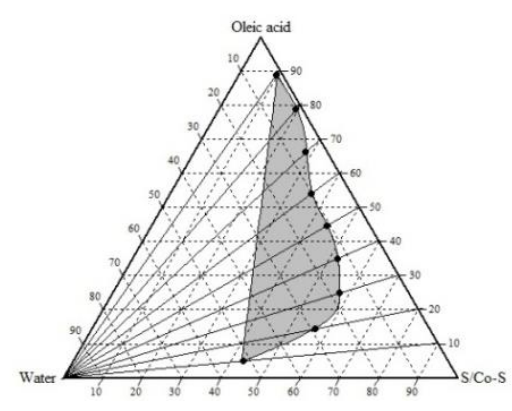

Figure 1. Pseudo-ternary phase diagram of microemulsion system under $\mathrm{Km}=1: 1 \mathrm{~S} / \mathrm{Co}-\mathrm{S}$ : Surfactant (Labrasol)/Co-surfactant (Transcutol P). 
The microemulsions distinguish from conventional emulsion systems by meaning with various characterisation properties. These colloidal carriers are isotropic, $<100 \mathrm{~nm}$ in size, monodisperse, thermodynamically stable and exhibiting Newtonian flow with low viscosity systems [21]. Hence, characterisation studies of these systems should be performed to verify formation of the microemulsions. All of the microemulsions exhibited isotropic property in current study. The photomicrographs of microemulsion (data not given) also depicted no birefringence of the polarized light with incorporation of ETD into these systems, confirming no change in isotropic behaviour. In addition to cross-polarized light microscopy images, the refractive index values of ETD loaded microemulsions (ME1-ME3) (Table 1) also indicated that they were optically isotropic systems. The refractive indices of drug loaded microemulsions were similar to those of their plain counterparts. Moreover, as water content in the microemulsions increased from 16 to $32 \%$, the refractive index values decreased from 1.44 to 1.42 because of lower refractive index of water in comparison with that of component of the formulation as also reported by Coneacet al. [22].

Table 1. Physicochemical characteristics of the plain and ETD loaded microemulsions (mean $\pm S D, n=3$ ).

\begin{tabular}{|c|c|c|c|c|c|c|}
\hline & $\begin{array}{c}\text { Droplet size } \\
\text { (nm) }\end{array}$ & PDI & $\mathrm{pH}$ & $\begin{array}{c}\text { Conductivity } \\
(\mu \mathrm{S} / \mathrm{cm})\end{array}$ & $\begin{array}{c}\text { Viscosity } \\
(\mathrm{mPa})\end{array}$ & $\begin{array}{l}\text { Refractive } \\
\text { index }\end{array}$ \\
\hline $\begin{array}{l}\text { Plain } \\
\text { ME1 }\end{array}$ & $3.42 \pm 0.10$ & $0.27 \pm 0.03$ & $4.10 \pm 0.12$ & $1.54 \pm 0.04$ & n.d. & $1.4390 \pm 0.0002$ \\
\hline ME1 & $12.07 \pm 0.53$ & $0.30 \pm 0.01$ & $3.69 \pm 0.01$ & $1.72 \pm 0.02$ & $38.26 \pm 0.26$ & $1.4400 \pm 0.0001$ \\
\hline $\begin{array}{l}\text { Plain } \\
\text { ME2 }\end{array}$ & $4.41 \pm 0.08$ & $0.25 \pm 0.02$ & $4.18 \pm 0.12$ & $10.06 \pm 0.03$ & n.d. & $1.4210 \pm 0.0001$ \\
\hline ME2 & $5.97 \pm 0.07$ & $0.22 \pm 0.01$ & $3.79 \pm 0.01$ & $11.81 \pm 0.09$ & $26.09 \pm 0.22$ & $1.4220 \pm 0.0002$ \\
\hline $\begin{array}{l}\text { Plain } \\
\text { ME3 }\end{array}$ & $3.42 \pm 0.01$ & $0.21 \pm 0.03$ & $4.08 \pm 0.04$ & $3.60 \pm 0.04$ & n.d. & $1.4290 \pm 0.0002$ \\
\hline ME3 & $3.41 \pm 0.12$ & $0.26 \pm 0.05$ & $3.75 \pm 0.02$ & $3.98 \pm 0.05$ & $28.51 \pm 0.57$ & $1.4305 \pm 0.0001$ \\
\hline
\end{tabular}

n.d.: not determined

The droplet size of colloidal carriers is a crucial factor affecting their physical stability $[16,23]$. Additionally, the smaller size of the nano-carriers, the stronger the permeability into the skin [15]. According to dynamic light scattering measurements, the droplet size of plain microemulsion formulations were found in range of $3.42 \pm 0.01$ and $4.41 \pm 0.08 \mathrm{~nm}$ whereas the droplet size of ETD loaded counterparts ranged between $3.41 \pm 0.12$ and $12.07 \pm 0.53 \mathrm{~nm}$ (Table 1). The PDI of the formulations was found less than 0.5 (varied from $0.21 \pm 0.03$ to $0.30 \pm 0.01$ ), which specifies narrow size distribution with spherical shape of samples and monodisperse stable systems [14,24]. The incorporation of ETD caused an increase in droplet size of ME1 and ME2 which might be due to the ETD accumulation in the droplets' interfacial layers rather than staying in the continuous phase.

The electrical conductivity measurements are facilitated for assessment of microemulsion type [14,23]. Mehta and Kaur [25] reported that very low specific conductivity $(0.001-0.1 \mu \mathrm{S} / \mathrm{cm})$ has presumed as water in oil (w/o) microemulsion, considering to conductivity of pure water $(1.1-1.3 \mu \mathrm{S} / \mathrm{cm})$ [26]. Based on this background, electrical conductivity data confirmed the generation of $\mathrm{o} / \mathrm{w}$ types of microemulsions in the study (Table 1). Besides, electrical conductivity of microemulsions proportionally increased with percentage of formulation water volume raised in agreement with a previous report [27]. Incorporation of ETD significantly resulted in an increase electrical conductivity values of drug loaded microemulsions due to weak acidic character of ETD $(p<0.05)$.

The $\mathrm{pH}$ of plain microemulsions ranged from $4.08 \pm 0.04$ to $4.18 \pm 0.12$ (Table 1) due to relatively high amount of oleic acid in the formulations. The loading ETD into the microemulsions caused a slightly decrease $\mathrm{pH}$ of the formulations (in range of $3.69 \pm 0.01$ and $3.79 \pm 0.01$ ) due to the acidic character of ETD (pKa: 4.65) [28].

For topical preparations, excessive viscosity could lead slower diffusion of drug molecules from the formulation to the skin surface, thereby reducing drug delivery into the skin. Besides this, the viscosity of microemulsion is a function of component types and concentrations in the formulation $[10,12,23,29]$. Hence, viscosity values of the microemulsions significantly decreased with increasing water content in the formulation (Table 1 and Table 4) as reported by Coneacet al. [22]. Also, a linear relationship was monitored 
between viscosity and PDI of microemulsions (Table 1). This phenomenon could be attributed to increased concentration of oil phase and hence decreased emulsification ability in the formulations. Furthermore, ETD loaded microemulsion formulations exhibited high linear regression $\left(\mathrm{r}^{2}>0.99\right)$ values between shear stress and shear rate, indicating Newtonian's flow behaviour (Figure 2). They also had low viscosity values in range of $26.09 \pm 0.22$ and $38.26 \pm 0.26 \mathrm{mPa}$.s (Table 1), which is one of microemulsion characteristics, as reported in the previous studies [30-32].

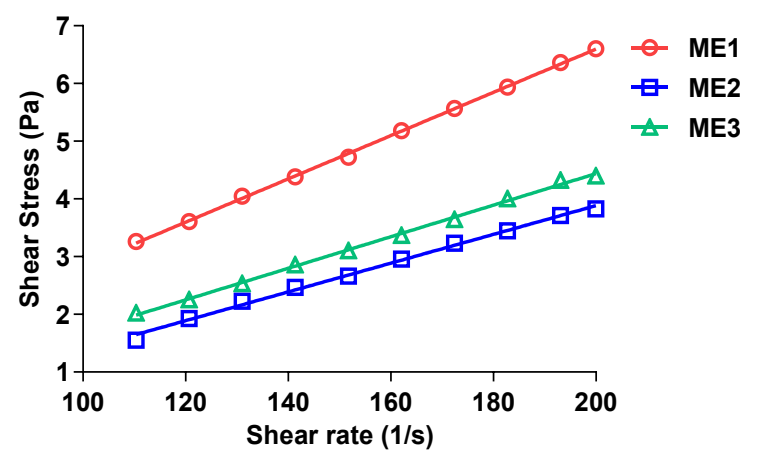

Figure 2. Rheological behaviour of ETD loaded microemulsions.

The morphological structure of ETD loaded ME3 formulation (as a representative formulation of microemulsions) was observed by TEM. As shown in Figure 3, TEM images indicated that droplets of the microemulsion were spherical, nano-sized and discrete with uniform distribution in the outer continuous aqueous phase.

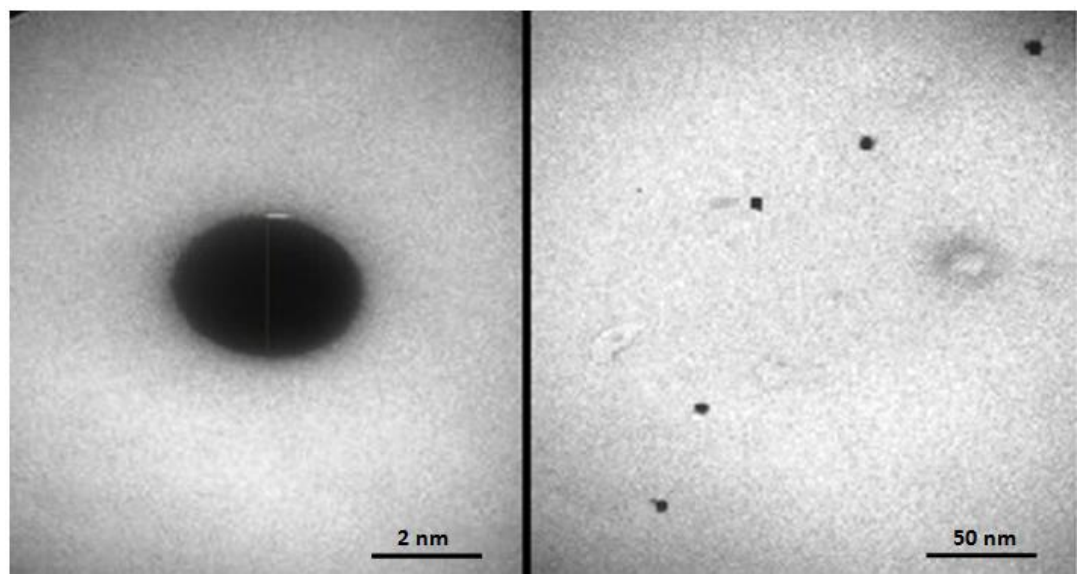

Figure 3. Transmission electron micrograph (TEM) of microemulsion droplets from ME3 formulation. The scale bar in the bottom of the picture represents $2 \mathrm{~nm}$ and $50 \mathrm{~nm}$ in length.

All of ETD loaded microemulsions showed no phase separation or drug precipitation, after centrifugation at $15000 \mathrm{rpm}$ for $30 \mathrm{~min}$, indicating the thermodynamic stability of the microemulsions. Also, the microemulsions exhibited no phase separation, turbidity or drug precipitation after 3 months of storage at long term condition. Afterwards, droplet size and PDI of the formulations were measured because determination of droplet size and distribution is one of the most important parameters for evaluating physical stability of microemulsions [33]. Evaluating measurements of droplet size and PDI, all of ETD loaded microemulsion formulations could be considered as a physically stable system for 3 months (Table 2).

The skin permeation of ETD from microemulsions was measured in vitro using excised porcine skin. The cumulative percutaneous penetrating amounts of ETD from the microemulsions ME1-ME3 and from the control formulation are illustrated in Figure 4 and, the permeation parameters are summarized in Table 3. 
Table 2. Physical stability of ETD loaded microemulsions for 3 months under long term condition $25^{\circ} \mathrm{C} \pm 2{ }^{\circ} \mathrm{C} / 60 \% \pm 5 \%$ relative humidity (mean $\pm \mathrm{SD}, n=3$ ).

\begin{tabular}{ccccc}
\hline & \multicolumn{3}{c}{$\mathbf{0}^{\text {th }}$ day } & \multicolumn{2}{c}{$3^{\text {rd } \text { month }}$} \\
\cline { 2 - 5 } & $\begin{array}{c}\text { Droplet size } \\
(\mathbf{n m})\end{array}$ & PDI & $\begin{array}{c}\text { Droplet size } \\
(\mathbf{n m})\end{array}$ & PDI \\
\cline { 2 - 5 } ME1 & $12.07 \pm 0.53$ & $0.30 \pm 0.01$ & $5.19 \pm 1.06$ & $0.32 \pm 0.03$ \\
ME2 & $5.97 \pm 0.07$ & $0.22 \pm 0.01$ & $5.10 \pm 0.09$ & $0.21 \pm 0.02$ \\
ME3 & $3.41 \pm 0.12$ & $0.26 \pm 0.05$ & $3.59 \pm 0.23$ & $0.28 \pm 0.06$ \\
\hline
\end{tabular}

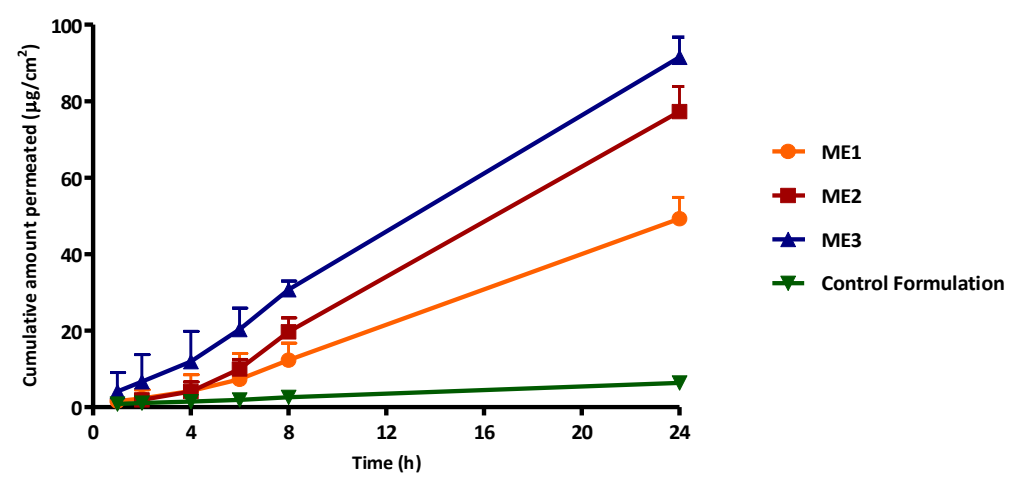

Figure 4. In vitro permeation profiles of ETD loaded microemulsions (mean $\pm S D, n=6$ ).

Table 3. The permeation parameters of ETD loaded microemulsions (mean $\pm S D, n=6$ )

\begin{tabular}{ccccc}
\hline Formulation Code & Flux $\left(\boldsymbol{\mu g} / \mathbf{c m}^{2} / \mathbf{h}\right)$ & $\mathbf{K}_{\mathrm{p}} \times \mathbf{1 0}^{-3}(\mathbf{c m} / \mathbf{h})$ & Lag time $(\mathbf{t})$ & $\mathbf{Q}_{24}\left(\boldsymbol{\mu g} / \mathbf{c m}^{2}\right)$ \\
\hline ME1 & $2.29 \pm 1.60$ & $0.46 \pm 0.32$ & $2.66 \pm 0.99$ & $49.31 \pm 5.56$ \\
ME2 & $3.67 \pm 1.87$ & $0.73 \pm 0.37$ & $2.42 \pm 1.58$ & $77.26 \pm 6.58$ \\
ME3 & $3.94 \pm 0.61$ & $0.79 \pm 0.12$ & $0.53 \pm 2.20$ & $91.52 \pm 5.26$ \\
Control Formulation & $0.24 \pm 0.07$ & $0.24 \pm 0.07$ & $-2.70 \pm 2.28$ & $6.35 \pm 1.46$ \\
\hline
\end{tabular}

Fluxes of ETD from the microemulsion formulations ME2 $\left(3.67 \pm 1.87 \mu \mathrm{g} \cdot \mathrm{cm}^{-2} \cdot \mathrm{h}^{-1}\right)$ and ME3 $(3.94 \pm 0.61$ $\left.\mu \mathrm{g} . \mathrm{cm}^{-2} \cdot \mathrm{h}^{-1}\right)$ were significantly higher than those of ME1 $\left(2.29 \pm 1.60 \mu \mathrm{g} \cdot \mathrm{cm}^{-2} \cdot \mathrm{h}^{-1}\right)$ and control formulation $\left(0.24 \pm 0.07 \mu \mathrm{g} . \mathrm{cm}^{-2} \cdot \mathrm{h}^{-1}\right)(p<0.05)$. The cumulative permeation of ETD in ME3 $\left(91.52 \pm 5.26 \mu \mathrm{g} / \mathrm{cm}^{2}\right)$ was 14 -fold higher than the value obtained for control formulation $\left(6.35 \pm 1.46 \mu \mathrm{g} / \mathrm{cm}^{2}\right)(p<0.05)$. There was no significant difference among lag time values of microemulsions $(p>0.05)$. Besides, the increase in drug fluxes from the microemulsion formulations was resulted in the decrease in lag time of ETD (Table 3). The ability of a microemulsion to improve the percutaneous penetration drugs is largely influenced by the composition and concentration of the microemulsion components, as well as the internal structure and type of the microemulsion used (o/w, w/o or bicontinuous systems) [34]. Transcutol $\mathrm{P}$ is a well-known penetration enhancer in skin delivery and by its amphiphilic nature, it has been known to reduce the interfacial tension resulting in balanced microemulsions systems. Transcutol $\mathrm{P}$ has been formulated at concentrations of up to $49.9 \%$ in topically applied FDA-approved products [35]. Our results demonstrated that the concentration of Transcutol $\mathrm{P}$ affected the permeation parameters of ETD.

The microemulsions have been proposed to alter the skin barrier function by affecting the stratum corneum intercellular lipids organization [34,36]. ATR-FTIR spectroscopy analysis was carried out to elucidate interaction between ETD microemulsions and the stratum corneum on the molecular level. This method could identify bands related to lipids, proteins and water in the stratum corneum, and the biochemical modifications in these bands after contact with permeation enhancers. In this technique, the symmetric and asymmetric C-H stretching vibrations describe the conformational order of the stratum corneum intercellular lipid chains. The blue shifts of these frequencies have been attributed to the conformational disordering of the lipids, which refers to an increase in motional freedom of the lipid hydrocarbon chain with the introduction of more gauche conformers in the stratum corneum lipids alkyl chains or due to phase separation. Figure 5 shows the effect of the microemulsions and their components on the frequencies of the $\mathrm{C}-\mathrm{H}$ symmetric and asymmetric absorbances. Compared to untreated control skin, the 
stretching vibrations were detected at higher wavenumbers in the skin samples treated either with microemulsions (ME1-ME3) or their components (oleic acid, Labrasol or Transcutol P), an observation indicating higher barrier permeability. Further, the changes in symmetric and asymmetric absorbances in the skin lipids after treatment of ME1 and ME3 formulations were significantly higher than that of ME2 formulation $(p<0.05)$. Considering compositions of the microemulsions, this phenomenon could be mainly attributed to higher concentration of oleic acid in ME1 and ME3 formulations (Table 4) because oleic acid is a liquid fatty acid which acts as a skin penetration enhancer. It has been shown that oleic acid produces separated fluid domains within the stratum corneum intercellular lipids and these domains are believed to offer a permeation pathway across the barrier [23]. In addition to this effect of oleic acid on lipid organisation of the stratum corneum, the partitioning of the surfactant (Labrasol) and the co-surfactant (Transcutol P) may have also contributed to the $\mathrm{C}-\mathrm{H}$ symmetric and asymmetric blue shifts as previously demonstrated [35,37]. Hence, it could be concluded that treatment with microemulsions contributes to increased fluidity of the stratum corneum lipids, which could have a great impact on the skin permeation enhancement of ETD.
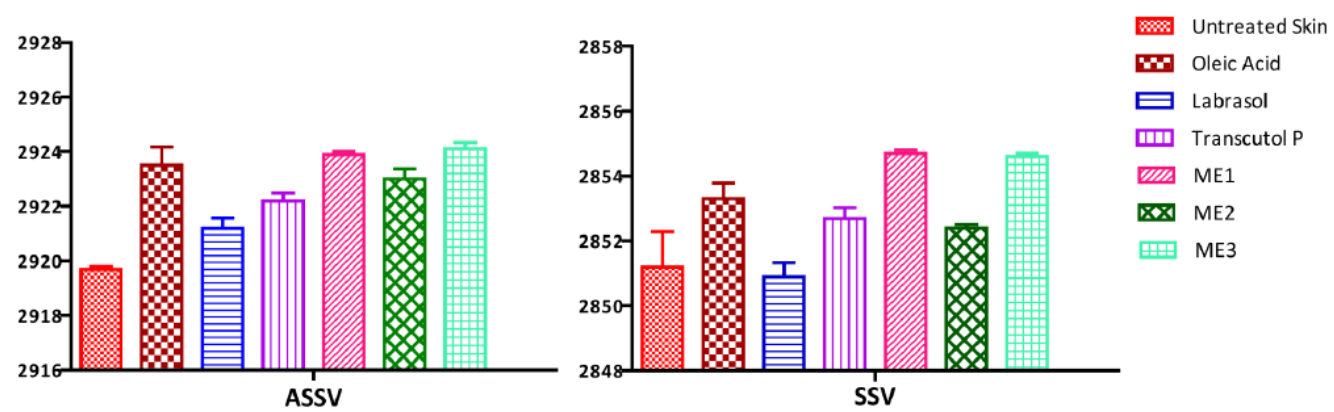

Figure 5. Changes of C-H symmetric and asymmetric stretching absorbances (SSV and ASSV) in the skin lipids after microemulsion and its components treatment.

CLSM is a useful visualization method that is used to observe drug delivery into the skin layers [38,39]. Figure $6 \mathrm{a}$ and $6 \mathrm{~b}$ are presented confocal images of Nile Red-loaded ME3 microemulsion and PBS suspension applied on the skin for $8 \mathrm{~h}$, respectively. In the images, Nile Red delivery from ME3 microemulsion into the skin was visualized up to $500 \mu \mathrm{m}$ in the XY-plane (Figure 6b). However, Nile Red released from PBS suspension was observed in depth of approximately $100 \mu \mathrm{m}$ (Figure 6a). Also, fluorescence intensity of skin applied on Nile Red-loaded microemulsion was more intense than those of the skin applied on PBS suspension (Figure 6a, b). This phenomenon demonstrated that ME3 microemulsion increased cutaneous uptake and permeation of lipophilic molecules into the skin compared to PBS suspension as also reported in a previous study [34,40]. Moreover, the confocal images were consistent with the results of in vitro permeation studies.

\section{CONCLUSION}

In the current study, microemulsion formulations of ETD were developed to enhance its permeation through the skin for topical treatment of inflammatory diseases. The formation and features of the microemulsions were verified by detailed characterisation studies. In vitro skin permeation studies indicated that delivery of ETD across skin was significantly increased by the optimized microemulsion formulations. ATR-FTIR spectroscopic analysis revealed that microemulsions overcome the stratum corneum barrier by fluidization of intercellular lipids. Additionally, CLSM images confirmed the penetration enhancement effect of microemulsion formulation consisting of oleic acid, Transcutol P, Labrasol, which are approved and widely used excipients in topical formulations.

Overall, the data support the optimized microemulsion formulation have significant potential for the enhanced topical delivery of ETD. Nevertheless, in vivo studies should be performed to emphasize topical anti-inflammatory efficiency of ETD microemulsion formulation. 

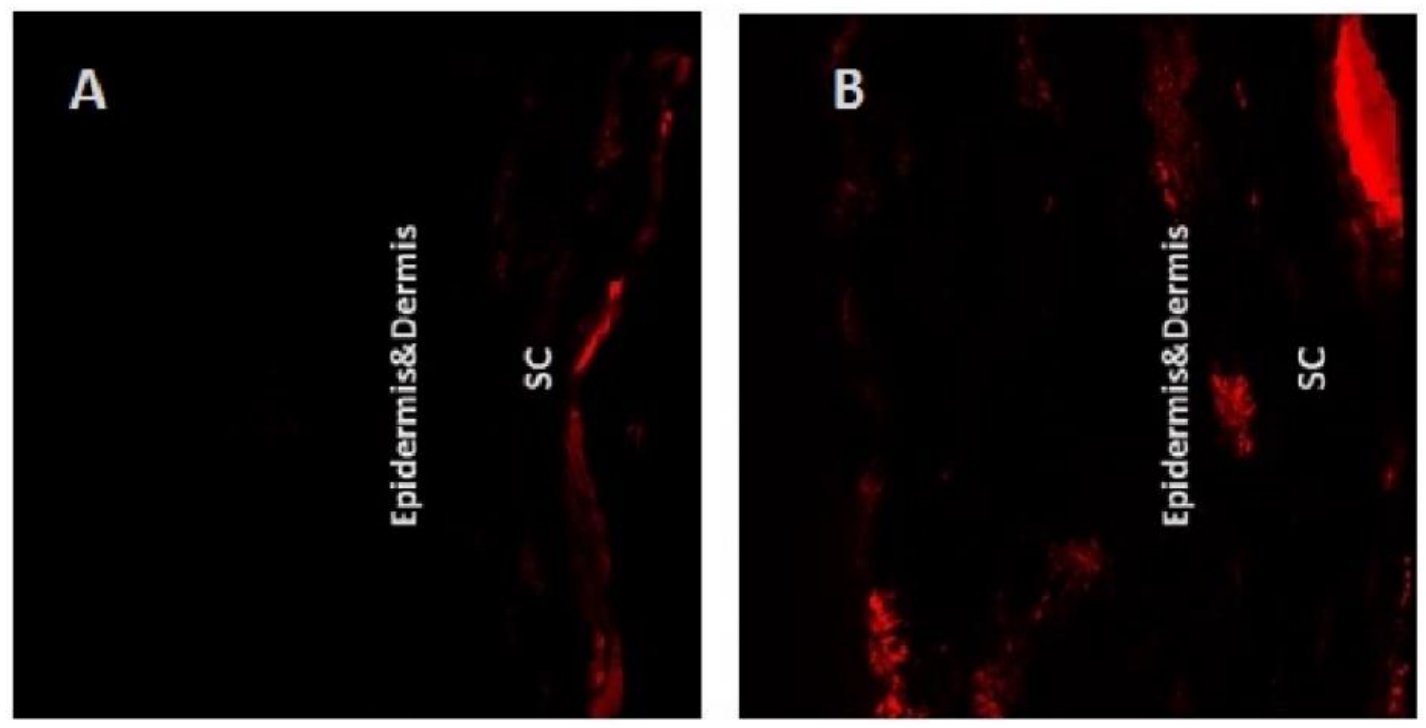

Figure 6. CLSM XY-images of mechanical cross-sections of the skin treated with A) Nile Red PBS suspension and B) Nile Red-loaded ME3 microemulsion for $8 \mathrm{~h}$.

\section{MATERIALS AND METHODS}

\subsection{Materials}

Etodolac (ETD) was kindly supplied by Nobel Drug Company (Istanbul, Turkey). Acetonitrile (ACN), 1,2-propanediol and o-phosphoric acid were purchased from Merck Millipore (Billerica, MA, USA). Oleic acid was provided from Sigma Aldrich (St Louis, MO, USA). Labrasol and Transcutol P were kind gifts of Gattefossé (Lyon, France).

\subsection{Methods}

\subsubsection{Solubility of ETD in microemulsion components}

Excess amount of ETD was added to oleic acid, Transcutol P, Labrasol and then, the mixtures were shaken at $25.0 \pm 0.5^{\circ} \mathrm{C}$ in an orbital shaker (IKA ${ }^{\circledR}$-Werke GmbH \& Co., Staufen, Germany) at $300 \mathrm{rpm}$ for $24 \mathrm{~h}$. The samples were kept at ambient temperature for $24 \mathrm{~h}$ for attaining equilibrium. The equilibrated samples were centrifuged for $15 \mathrm{~min}$ at $15000 \mathrm{rpm}$ to remove un-dissolved drug. The aliquots of supernatant were filtered ( $0.45 \mu \mathrm{m}$, Millex, Merck Millipore, Billerica, MA, USA) and ETD concentration was determined using HPLC analysis after appropriate dilution with ACN.

\subsubsection{Construction of pseudo-ternary phase diagrams}

The concentration ranges of components for existence of microemulsions were determined by construction of pseudo-ternary phase diagrams based on water titration method at ambient temperature $\left(25.0 \pm 0.5^{\circ} \mathrm{C}\right)$ [9]. Oil in water microemulsions were prepared by mixing oil (oleic acid), surfactant (Labrasol), and cosurfactant (Transcutol P), followed by gentle titration of distilled water. Two phase diagrams were performed with the $\mathrm{Km}$ (mass ratio of surfactant to co-surfactant) 1:1 and 1:2. The weight ratios of oleic acid to the mixture of surfactant and co-surfactant were varied from 1:9 to 9:1. The microemulsion formed spontaneously at room temperature as a clear, low viscous monophasic liquid. The stable microemulsions were also observed under polarizing light to confirm their isotropic nature. The pseudo-ternary phase diagrams were constructed using Triplot software version 4.1.2. The ratios with feasible emulsification were further tested.

\subsubsection{Preparation of ETD loaded microemulsion formulations}

Based on the pseudo-ternary phase diagrams with $\mathrm{Km} \mathrm{1:1} \mathrm{and} \mathrm{1:2,} \mathrm{three} \mathrm{different} \mathrm{types} \mathrm{of}$ microemulsion formulation were selected from the microemulsion region for incorporation of drug. ETD was dissolved in the mixture of oil, surfactant and co-surfactant. After complete solubilisation, distilled water was added drop-wise into this mixture under constant stirring (IKA RT10, Staufen, Germany). Then, 
ETD loaded microemulsions were stirred in order to provide equilibrium for $72 \mathrm{~h}$. The composition of ETD loaded microemulsions was presented in Table 4.

Table 4. Composition of optimized microemulsion formulations.

\begin{tabular}{lccc}
\hline $\begin{array}{l}\text { Microemulsion components } \\
(\% \text { w/w) }\end{array}$ & ME1 & ME2 & ME3 \\
\hline Oleic acid & 28 & 6.8 & 19.5 \\
Labrasol & 28 & 30.6 & 19.5 \\
Transcutol P & 28 & 30.6 & 39 \\
Water & 16 & 32 & 22 \\
S/Co-S & $1: 1$ & $1: 1$ & $1: 2$ \\
Etodolac & 5 & 5 & 5 \\
\hline
\end{tabular}

\subsubsection{Characterisation of microemulsion formulations}

In order to verify the isotropic nature of the prepared microemulsion formulations, cross-polarized light microscopy (Olympus CX31-P, Tokyo, Japan) imaging was performed. A drop of freshly prepared microemulsion was placed between a cover slip and a glass slide, and then the images were examined under cross-polarized light using a magnification of x10.

The refractive index of the microemulsions was measured by a digital Abbe Refractometer (Atogo Co. Ltd., Tokyo, Japan) by placing a drop of each microemulsion formulation on the slide at $25^{\circ} \mathrm{C}$.

The droplet size and polydispersity index (PDI) of the plain and ETD loaded microemulsions were determined using dynamic light scattering (Malvern Zetasizer Nano ZS, Malvern Instruments, Worcestershire, UK) after pre-filtering $(0.45 \mu \mathrm{m}$, Millex, Merck Millipore, Billerica, MA, USA) of the microemulsions. The microemulsion samples were loaded into disposable cuvettes having a volume of $1 \mathrm{~mL}$ without diluting at $25.0 \pm 0.5^{\circ} \mathrm{C}$.

The electrical conductivity of the plain and ETD loaded microemulsions were determined using a calibrated conductometer (Bench 2700 Serie, EuTech Instruments, Landsmeer, Netherlands) at a frequency of $94 \mathrm{~Hz}$. The $\mathrm{pH}$ of the microemulsions was measured by a calibrated $\mathrm{pH}$ meter (EuTech Instruments) at room temperature.

The viscosity and rheological behaviour of ETD loaded microemulsions were evaluated by a Brookfield Rheometer (Brookfield R/S-SST, Middleboro, MA, USA) with a cone-plate at $25 \pm 2^{\circ} \mathrm{C}$. The measurements were performed with shear rates in range of $0-200 \mathrm{~s}^{-1}$ for $240 \mathrm{~s}$. The rheological behaviour of the microemulsion formulations was evaluated by constructing rheograms where the shear stress (Pa) versus shear rate $\left(\mathrm{s}^{-1}\right)$ was plotted. Then, the viscosity values of microemulsions were calculated from slope of shear stress-shear rate plots.

The morphology of the selected microemulsion formulation (ME3) was determined by Transmission Electron Microscopy (TEM) (FEI Company-TecnaiTM G2 Spirit/Biotwin, Hillsboro, Oregon, USA). In order to perform the analysis a drop of the microemulsion was deposited on the copper grid. $100 \mu \mathrm{L}$ of $2 \%$ aqueous solution of phosphotungstic acid was dropped onto the grid and left for 2 min negative staining. Excess of staining solution was gently removed with a filter paper and the grid was air-dried at room temperature prior to the analysis. Then, the sample was visualized at 5000-50000 magnification with an accelerating voltage of $80 \mathrm{kV}$.

The thermodynamic stability of ETD loaded microemulsions was assessed by centrifugation at 15000 rpm for 30 minutes, then observing visually for phase separation. Additionally, the physical stability of ETD loaded microemulsions in well-stoppered glass containers were monitored for 3 months under long term condition $25^{\circ} \mathrm{C} \pm 2{ }^{\circ} \mathrm{C} / 60 \% \pm 5 \%$ relative humidity $(\mathrm{RH})$ as stated in International Conference on Harmonisation $(\mathrm{ICH})$ guideline. The physical stability of formulations was periodically examined for any appearance change (optical clarity, phase separation, precipitation of drug) and measurement of mean droplet size and PDI at 0 - and 3-month storage.

\subsubsection{Etodolac quantification method}

The quantification of ETD in the permeation studies was conducted by a HPLC equipped with UV detector (Shimadzu Model LC 20AT, Kyoto, Japan). An octadecylsilane (ODS) $\mathrm{C}_{18}$ solid phase column (4.6 $\mathrm{mm} \times 150 \mathrm{~mm}, 5 \mu \mathrm{m}$, Agilent Technologies, Inc., Cary, NC, USA) was used as stationary phase. The mobile phase consisted of acetonitrile: water: phosphoric acid (500:500:0.25) and the flow rate was fixed at 1.5 
mL.min ${ }^{-1}$. The wavelength of detection was set at $275 \mathrm{~nm}$. The limit of quantification was found 0.190 $\mu \mathrm{g} / \mathrm{mL}$. The method was validated for selectivity, linearity, accuracy and precision. It was found to be linear in concentration range of $0.25-100 \mu \mathrm{g} / \mathrm{mL}$ with a high correlation coefficient $\left(\mathrm{r}^{2}=0.9999\right)$, precise (intra- and inter-day variation $<2 \%$ ) and accurate (mean recovery $>99 \%$ ). Comparison of the chromatograms obtaining from extracted porcine skin did not reveal any interfering peaks with ETD, confirming selectivity of the method.

\subsubsection{In vitro permeation tests}

\section{Preparation of excised skin}

Porcine skin (obtained from a local slaughterhouse) was cleaned from fat and muscle, and then dermatomed to a thickness of $750 \mu \mathrm{m}$ (Zimmer Electric Dermatome, Warsaw, IN, USA). The integrity of the skin was confirmed by transepidermal water loss (TEWL) measurement with the open chamber device (Tewameter TM 300, Courage-Khazaka, Cologne, Germany).

\section{Permeation of ETD though the skin}

Skin permeation of ETD was examined using Franz type diffusion cells (diffusion area of $1.77 \mathrm{~cm}^{2}$, Permegear V6A Stirrer, Hellertown, PA, USA) [40]. The skin was placed on the receiver chambers with the stratum corneum facing upwards and then the donor chambers were clamped in place. The receptor chambers were filled with $12 \mathrm{~mL}$ of phosphate-buffered saline (PBS, $\mathrm{pH} 7.4$ ): 1,2-propanediol mixture (70:30, v/v). The receptor phases maintained at $37.0 \pm 1.0^{\circ} \mathrm{C}$ under constant stirring $(300 \mathrm{rpm})$ with a magnetic bar. The microemulsion formulations containing $5 \%(\mathrm{w} / \mathrm{w})$ of ETD $(0.1 \mathrm{~mL})$ were placed in the donor compartments of diffusion cells up. The donors were sealed by Parafilm $\mathrm{M}^{\circledR}$ (Bemis, Oshkosh, WI, USA) immediately after addition of the formulations in order to prevent evaporation. The permeation of ETD from microemulsions was followed for $24 \mathrm{~h}$. The samples of $500 \mu \mathrm{L}$ were removed at appropriate time intervals for analysis and replaced immediately by fresh receptor medium. The samples were analyzed for their drug content by HPLC as described above.

Permeation profiles of ETD were constructed by plotting time (hour) against the cumulative amount of the drug $\left(\mu \mathrm{g} / \mathrm{cm}^{2}\right)$ measured in the receptor medium. Steady state fluxes $\left(\mathrm{Js}, \mu \mathrm{g} / \mathrm{cm}^{2} . \mathrm{h}\right)$ were calculated from the steady state part of the curves. In order to obtain the permeability coefficients $\mathrm{Kp}$, the following equation was used: $\mathrm{Kp}=\mathrm{Js} / \mathrm{C}_{\text {donor, }}$ where $\mathrm{C}_{\text {donor }}$ represents the applied drug concentration in the donor compartment.

\section{Permeation mechanism of ETD through the skin}

To assess the interaction between ETD loaded microemulsions and the stratum corneum was performed on ATR-FTIR spectroscopy studies at the end of $24 \mathrm{~h}$ in vitro permeation studies as described previously [34]. The microemulsion components oleic acid, Labrasol and Transcutol P were applied to porcine skin under identical in vitro conditions, and their effect on the skin was studied by ATR-FTIR spectroscopy after the skin surface was cleaned gently. The ATR-FTIR spectra were taken in the frequency range of 4000-650 $\mathrm{cm}^{-1}$ with a spectral resolution of $4 \mathrm{~cm}^{-1}$ using an FTIR spectrometer (Perkin Elmer Spectrum 100 FT-IR Spectrometer, Shelton, CT, USA). The internal reflection element was a ZnSe crystal with a trapezoidal cut at $45^{\circ}$. The peak positions were determined using Perkin Elmer Spectrum Version 6.0.2 software. The frequency shifts of the C-H symmetric and asymmetric stretching absorbance, (at 2850 and $2920 \mathrm{~cm}^{-1}$, respectively) which are sensitive to perturbations in the conformational order of the stratum corneum intercellular lipids, are investigated.

\subsubsection{Fluorescence distribution in the skin}

Confocal laser scanning microscopy (CLSM) analysis was performed to provide information about poorly soluble drug molecule's delivery behaviour from the microemulsion into the skin layers[34]. A lipophilic fluorescent dye, Nile Red $(0.05 \%$, w/w) as model compound, was loaded into ME3 microemulsion, which provided the highest skin permeation of ETD. Nile Red loaded ME3 microemulsion and control formulations were treated to the porcine skin for $8 \mathrm{~h}$ under the same in vitro skin permeation study conditions. A Nile Red PBS suspension $(0.05 \% \mathrm{w} / \mathrm{w})$ was used as the control. Then, the skin surface was cleaned carefully with physiological buffer ( $\mathrm{pH}$ : 7.4), and wiped gently. The skin samples were treated with OCT (Optimal Cutting Temperature) matrix (Tissue-Tek ${ }^{\mathrm{TM}} \mathrm{Cryo}$ ) and frozen at $-20^{\circ} \mathrm{C}$. Afterwards, the frozen skin samples were cut into vertical slices of approximately $10 \mu \mathrm{m}$ thickness by a cryotome 
(ThermoScientific ${ }^{\mathrm{TM}}$ Cryotome, USA). Nile Red delivery into the skin layers was examined with CLSM (Leica Microsystems, TCS-SPE, Wetzlar, Germany), which was equipped with a HeNe diode laser (excitation and emission line at $543 \mathrm{~nm}$ and $630 \mathrm{~nm}$, respectively). The confocal images were obtained in the plane of the $\mathrm{XY}$ - planes.

\subsubsection{Statistical analysis}

The results are presented as mean values of at least three experiments \pm standard deviation (SD). The statistical data analysis was performed by one-way analysis of variance (ANOVA) using GraphPad Prism Software version $6.05^{\circledR}$ (La Jolla, CA, USA). A multiple comparison test was used to compare different formulations and $p<0.05$ was considered as significant.

Acknowledgements: This research was financially supported by Istanbul University Scientific Research Projects under the number of 19204

Author contributions: Concept - M.S.E., S.G.; Design - G.S., S.G.; Supervision - M.S.E., S.G.;Resources - M.S.E., S.G.;Materials - G.S., S.G.; Data Collection and/or Processing - G.S., E.K.; Analysis and/or Interpretation - E.K., S.G.; Literature Search - E.K., M.S.E.; Writing - E.K., M.S.E.; Critical Reviews - G.S., E.K., M.S.E., S.G.

Conflict of interest statement: The authors declared no conflict of interest.

\section{REFERENCES}

[1] Lionberger D, Brennan M. Topical Nonsteroidal Anti-Inflammatory Drugs for the Treatment of Pain due to Soft Tissue Injury: Diclofenac Epolamine Topical Patch. J Pain Res. 2010;3:223-233.

[2] Okyar A, Özsoy Y, Güngör S. Novel Formulation Approaches for Topical and Transdermal Delivery of NonSteroidal Anti-Inflammatory Drugs. In: Lemmey A.Editor. Rheumatoid Arthritis- Treatment, Rijeka: IntechOpen; 2012, pp. 25-48.[CrossRef]

[3] Varga Z, Sabzwari SRA, Vargova V. Cardiovascular Risk of Nonsteroidal Anti-Inflammatory Drugs: An UnderRecognized Public Health Issue. Cureus. 2017;9(4): i1144.

[4] Alomrani AH, Badran MM. Flexosomes for Transdermal Delivery of Meloxicam: Characterization and AntiInflammatory Activity. Artif Cells, Nanomedicine, Biotechnol. 2017;45(2):305-312.

[5] Brown M, Martin G, Jones S, Akomeah F. Dermal and Transdermal Drug Delivery Systems: Current and Future Prospects. Drug Deliv. 2006;13(3):175-187. [CrossRef]

[6] Erdal MS, Güngör S, Özsoy Y. Biopolymers: Dermal and Transdermal Drug Delivery Systems. In: Mishra A.Editor. Encyclopedia of Biomedical Polymers and Polymeric Biomaterials. 1st Edition, New York: Taylor \& Francis; 2015, pp. 2606-2019.

[7] https://pubchem.ncbi.nlm.nih.gov/compound/Etodolac

[8] Benbow T, Campbell J. Microemulsions as Transdermal Drug Delivery Systems for Non-Steroidal AntiInflammatory Drugs (NSAIDs): A Literature Review. Drug Dev Ind Pharm. 2019;45(12):1849-1855.

[9] Sharma AK, Garg A, Goyal A, Rath G. Role of Microemulsions in Advanced Drug Delivery. Artif Cells, Nanomedicine, Biotechnol An Int J. 2016;44(4):1177-1185.

[10] Todosijevic M, Savic M, Batinic B, Markovic B, Gašperlin M, Ranpelovic D, et al. Biocompatible Microemulsions of a Model NSAID for Skin Delivery: A Decisive Role of Surfactants in Skin Penetration/Irritation Profiles and Pharmacokinetic Performance. Int J Pharm. 2015;496(2):931-941. [CrossRef]

[11] Güngör S, Erdal MS, Güngördük S. Colloidal Carriers in the Topical Treatment of Dermatological Diseases. In: Naik J.Editor. Nano Based Drug Delivery, Zagreb: IAPC publishing; 2015, pp. 391-409.

[12] Mahrhauser D, Kählig H, Partyka-Jankowska E, Peterlik H, Binder L, Kwizda K, et al. Investigation of Microemulsion Microstructure and its Impact on Skin Delivery of Flufenamic Acid. Int J Pharm. 2015;490(1-2):292297.[CrossRef]

[13] Sintov A. Transdermal Delivery of Curcumin viaMicroemulsion. Int J Pharm. 2015;481(1-2):97-103, [CrossRef]

[14] Goindi S, Kaur R, Kaur R. An Ionic Liquid-in-Water Microemulsion as a Potential Carrier for Topical Delivery of Poorly Water Soluble Drug: Development, Ex-vivo and In-vivo Evaluation. Int J Pharm. 2015;495(2):913923.[CrossRef] 
[15] Zhang Y, Zhang K, Wang Z, Hu H, Jing Q, Li Y, et al. Transcutol ${ }^{\circledR}$ P/Cremophor ${ }^{\circledR}$ EL/Ethyl Oleate-Formulated Microemulsion Loaded into Hyaluronic Acid-Based Hydrogel for Improved Transdermal Delivery and Biosafety of Ibuprofen. AAPS PharmSciTech. 2019;21(1):22.[CrossRef]

[16] Hoppel M, Juric S, Ettl H, Valenta C. Effect of Monoacyl Phosphatidylcholine Content on the Formation of Microemulsions and Dermal Delivery of Flufenamic Acid. Int J Pharm. 2015;479(1):70-76.[CrossRef]

[17] Erdal MS, Ozhan G, Mat MC, Ozsoy Y, Gungor S. Colloidal Nanocarriers for the Enhanced Cutaneous Delivery of Naftifine: Characterization Studies and In-vitro and In-vivo Evaluations. Int J Nanomedicine. 2016;11:10271037.[CrossRef]

[18] Javadzadeh Y, Adibkia K, Hamishekar H.Transcutol ${ }^{\circledR}$ (Diethylene Glycol Monoethyl Ether): A Potential Penetration Enhancer. In: Dragicevic N, Maibach HI. Editors. Percutaneous Penetration Enhancers Chemical Methods in Penetration Enhancement. Heidelberg: Springer-Verlag. 2015, pp. 195-205.[CrossRef]

[19] Rhee YS, Choi JG, Park ES, Chi SC. Transdermal Delivery of Ketoprofen Using Microemulsions. Int J Pharm. 2001;228(1-2):161-170.[CrossRef]

[20] Lopes LB. Overcoming the Cutaneous Barrier with Microemulsions. Pharmaceutics. 2014;6(1):52-77. [CrossRef]

[21] Formariz T, Urban M, Silva Júnior A. Microemulsion and Liquid Crystals as Drug Delivery Systems. Brazilian J Pharm Sci. 2005;41:301-313.

[22] Coneac G, Vlaia V, Olariu I, Muț AM, Anghel DF, Ilie C, et al. Development and Evaluation of New Microemulsion-Based Hydrogel Formulations for Topical Delivery of Fluconazole. AAPS PharmSciTech. 2015;16:889-904.[CrossRef]

[23] Hathout R, Woodman T, Mansour S, Mortada N, Geneidi A, Guy R. Microemulsion Formulations for the Transdermal Delivery of Testosteron. Eur J Pharm Sci. 2010;40(3):188-196.[CrossRef]

[24] Mahboobian MM, Mohammadi M, Mansouri Z. Development of Thermosensitive In-situ Gel Nanoemulsions for Ocular Delivery of Acyclovir. J Drug Deliv Sci Technol. 2020;55:101400.[CrossRef]

[25] Mehta S, Kaur G. Microemulsions: Thermodynamic and Dynamic Properties. In: Tadashi M.Editor. Thermodynamics, In Tech; 2011, pp. 382-409.[CrossRef]

[26] Pidaparthi K, Suares D. Comparison of Nanoemulsion and Aqueous Micelle Systems of Paliperidone for Intranasal Delivery. AAPS PharmSciTech. 2017;18:1710-1719.[CrossRef]

[27] Ma H, Yu M, Lei M, Tan F, Li N. A Novel Topical Targeting System of Caffeine Microemulsion for Inhibiting UVBInduced Skin Tumor: Characterization, Optimization, and Evaluation. AAPS PharmSciTech. 2015;16:905913.[CrossRef]

[28] Martindale the Complete Drug Delivery. 34th ed. Londra: 2005.

[29] Lou H, Qiu N, Crill C, Helms R, Almoazen H. Development of W/O Microemulsion for Transdermal Delivery of Iodide Ions. AAPS PharmSciTech. 2013;14:168-176.[CrossRef]

[30] Patel MR, Patel RB, Parikh JR, Solanki AB, Patel BG. Effect of Formulation Components on the In-vitro Permeation of Microemulsion Drug Delivery System of Fluconazole. AAPS PharmSciTech. 2009;10:917-923.[CrossRef]

[31] Goindi S, Arora P, Kumar N, Puri A. Development of Novel Ionic Liquid-Based Microemulsion Formulation for Dermal Delivery of 5-Fluorouracil. AAPS PharmSciTech. 2014;15:810-821.[CrossRef]

[32] Chaiyana W, Anuchapreeda S, Leelapornpisid P, Phongpradist R, Viernstein H, Mueller M. Development of Microemulsion Delivery System of Essential Oil from Zingiber cassumunar Roxb. Rhizome for Improvement of Stability and Anti-Inflammatory Activity. AAPS PharmSciTech. 2017;18:1332-1342.[CrossRef]

[33] Sousa GD, Kishishita J, Aquino KAS, Presgrave OAF, Leal LB, Santana DP. Biopharmaceutical Assessment and Irritation Potential of Microemulsions and Conventional Systems Containing Oil from Syagrus cearensis for Topical Delivery of Amphotericin B Using Alternative Methods. AAPS PharmSciTech. 2017;18:1833-1842.[CrossRef]

[34] Gürbüz A, Özhan G, Güngör S, Erdal MS. Colloidal Carriers of Isotretinoin for Topical Acne Treatment: Skin Uptake, ATR-FTIR and In-vitro Cytotoxicity Studies. Arch Dermatol Res. 2015;307:607-615.[CrossRef]

[35] Osborne DW, Musakhanian J. Skin Penetration and Permeation Properties of Transcutol(R)-Neat or Diluted Mixtures. AAPS PharmSciTech. 2018;19:3512-3533.[CrossRef]

[36] Carvalho ALM, Silva JA, Lira AAM, Almeida EDP, Nunes R de S, Sarmento VHV, et al. Third-Generation Transdermal Delivery Systems Containing Zidovudine: Effect of the Combination of Different Chemical Enhancers and a Microemulsion System. AAPS PharmSciTech. 2018;19:3219-3227.[CrossRef] 
[37] Caddeo C, Manconi M, Valenti D, Maccioni AM, Fadda AM, Sinico C. The Role of Labrasol ${ }^{\circledR}$ in the Enhancement of the Cutaneous Bioavailability of Minoxidil in Phospholipid Vesicles. Res J Pharm Technol. 2012;5(12):1563-1569.

[38] Hathout RM, Mansour S, Geneidi AS, Mortada ND. Visualization, Dermatopharmacokinetic Analysis and Monitoring the Conformational Effects of a Microemulsion Formulation in the Skin Stratum Corneum. J Colloid Interface Sci. 2011;354(1):124-130.[CrossRef]

[39] Rossetti F, Depieri L, Bentley M. Confocal Laser Scanning Microscopy as a Tool for the Investigation of Skin Drug Delivery Systems and Diagnosis of Skin Disorders. In: Lagali N. Editor. Confocal Laser Microscopy - Principles and Applications in Medicine, Biology, and the Food Sciences. Croatia: IntechOpen; 2013, pp. 99-140.[CrossRef]

[40] Qurt M, Esentürk İ, Birteksöz Tan S, Erdal MS, Araman A, Güngör S. Voriconazole and Sertaconazole Loaded Colloidal Nano-Carriers for Enhanced Skin Deposition and Improved Topical Fungal Treatment. J Drug Deliv Sci Technol. 2018;48:215-222.[CrossRef]

This is an open Access article which is publicly available on our journal's website under Institutional Repository at http://dspace.marmara.edu.tr. 